\title{
FORMAÇÃO DE PROFESSORES PARA EDUCAÇÃO PROFISSIONAL NO BRASIL: PERCURSO HISTÓRICO E DESAFIOS CONTEMPORÂNEOS
}

\section{Resumo}

Francisco das Chagas Silva Souza ${ }^{1}$ Iaponira da Silva Rodrigues ${ }^{2}$

Neste artigo, destacamos e contextualizamos historicamente algumas medidas tomadas pelo Estado brasileiro, voltadas para a formação de docentes para atuar na Educação Profissional, principalmente no século XX. Discutimos também os desafios para essa formação no contexto atual. A metodologia constou de pesquisa bibliográfica e de consultas à legislação acerca da formação docente para a Educação Profissional. Concluímos que essa formação, no século passado, foi realizada a partir de cursos emergenciais, rápidos e voltados às exigências do mercado. $\mathrm{O}$ atual cenário histórico apresenta desafios ainda maiores para a formação inicial e continuada desses docentes, em função da expansão da oferta da Educação Profissional, das especificidades desta modalidade e das exigências que estas impõem ao professor que, muitas vezes, nela se insere sem uma base pedagógica que oriente as suas práticas.

Palavras-chave: História da educação profissional. Formação de professores. Prática docente.

\section{TEACHERS' FORMATION FOR PROFESSIONAL EDUCATION IN BRAZIL: HISTORICAL TRAJECTORY AND CONTEMPORARY CHALLENGES}

\begin{abstract}
This paperdiscusses and, historically, contextualizessomemeasurescarried out by the Brazilian State on the teachers' formation for Professional Education, especially in the 20th century. Wealsoponder about the current challenges for thisprocess in the current scenario. The methodologywasbased on bibliographicalresearch, as well as documents, decrees and legislation for the teachers' formation for Professional Education. The results show that, during the last century, the teachers' formation for Professional Education wasconceivedfrom emergency courses, whichwere short and alignedwith the interests of the market. The currenthistorical scenario presentsevenbigger challenges towards initial and continued formation of thoseteachersbecause of the expansion of Professional Education, the specificities of thatmodality and the demandsimposed onto teacherswhooftenstartworkingwith Professional Education without a pedagogical base to guide their practice.
\end{abstract}

Keywords: History of professional education. Teachers' formation. Teaching practice. 


\section{Revista IIIS'THEIBR On-lime

\section{INTRODUÇÃO}

"Entre as lacunas existentes na história da educação no Brasil, a da educação profissional não é das menores", afirma Cunha (2005a, p. 1) ao iniciar a introdução de uma de suas obras. A constatação desse autor é confirmada em algumas pesquisas. Urbanetz (2012), ao realizar uma investigação no site da Coordenação de Aperfeiçoamento de Pessoal de Nível Superior (CAPES) e da Associação Nacional de Pós-Graduação e Pesquisa em Educação (ANPED), concluiu que, entre os anos 2000 e 2009, há uma "[...] precariedade de produção de conhecimento sobre a formação de professores para a educação profissional, ainda que este seja um tema de análise urgente diante da importância que a educação profissional tem no cenário nacional”. (URBANETZ, 2012, p. 870). Oliveira (2016), com o objetivo de mapear a produção acerca da formação docente para a Educação Profissional, encontrou apenas 34 estudos nos bancos de dissertações e teses da Capes e da biblioteca virtual do Instituto Brasileiro de Informação em Ciência e Tecnologia (IBICT) entre os anos 2004 e 2014. Para essa pesquisadora "[...] os dados revelam que essa temática ainda é incipiente". (2016, p. 6).

Se a produção do conhecimento acerca da história da Educação Profissional é reduzida, como também o é quando o foco é a formação de professores para essa modalidade, não poderia ser diferente a produção acadêmica a respeito da história da formação inicial e continuada para os docentes que nela atuam ou que atuarão.

Nosso objetivo, neste artigo, é discutir ações realizadas pelo Estado brasileiro voltadas à formação de docentes para atuar na Educação Profissional, com ênfase no século passado. Entretanto, alertamos aos leitores que, nos limites deste artigo, é impossível debater todas as medidas tomadas pelo poder público com esse fim. Daremos destaque às que consideramos mais relevantes.

A metodologia constou de uma pesquisa exploratória, visto que visamos apresentar uma visão panorâmica de um tema ainda pouco explorado. (GIL, 2012; GONSALVES, 2007). Também recorremos a uma pesquisa bibliográfica em obras que tratam da formação docente para a Educação Profissional no Brasil, além de consultas à legislação que trata desse tema.

Assim, face ao nosso objetivo, no decorrer deste artigo, pontuamos e analisamos algumas medidas tomadas pelos governos brasileiros ao longo do século XX e finalizamos o texto com uma discussão acerca dos impasses que enfrenta a formação de professores para a Educação Profissional no cenário contemporâneo, quando as instituições federais que ofertam essa modalidade vivem os efeitos da maior expansão de sua história.

\section{FORMAÇÃO DOCENTE PARA A EDUCAÇÃO PROFISSIONAL: MAPEAMENTO DAS AÇÕES DO ESTADO}


Historicamente, as iniciativas em prol da formação de professores para a Educação Profissional, no Brasil, foram poucas e descontínuas. A literatura aponta como marco inicial dessas iniciativas, a criação da Escola Normal de Artes e Ofícios Venceslau Brás por meio do Decreto ${ }^{\circ} 1.880$, de 11 de agosto de 1917, no Distrito Federal (à época, o Rio de Janeiro). Essa instituição era resultado de uma parceria firmada entre a União e a Prefeitura do Distrito Federal e, embora tenha sido inaugurada em 09 de novembro de 1918, seu funcionamento só teve início quase um ano depois, em 11 de agosto de 1919.

A princípio, a Escola Normal de Artes e Ofícios Venceslau Brás tinha uma dupla finalidade: "[...] preparar professores, mestres e contramestres para estabelecimentos de ensino profissional, assim como professores de trabalhos manuais para as escolas primárias da municipalidade [...]". (CUNHA, 2005b, p. 83). Todavia, em 1919, André Gustavo Paulo de Frontin, ao assumir a prefeitura do Distrito Federal, realizou uma inspeção nessa escola e, julgando que o funcionamento desta iria ser oneroso, além de considerar restrita a sua finalidade (formar professores somente para as escolas pertencentes ao município), passou a defender o seu fechamento, decisão que suscitou intensos debates e resistências no meio educacional.

Para contornar a crise, a Escola Normal de Artes e Ofícios Venceslau Brás foi transferida para a esfera federal. Tal decisão atendia, de um lado, às inquietações postas pelo prefeito Paulo Frontin, e, de outro, à carência de formação de professores para atuar nos estabelecimentos criados em setembro de 1909, pelo presidente Nilo Peçanha, as Escolas de Aprendizes Artífices, as quais, um século depois viriam a constituir os atuais IFs. Após um período de negociações, em novembro de 1919, foi celebrado o acordo de transferência da administração daquela escola para a esfera federal.

Inicialmente, naquela instituição, só era admitido o ingresso de candidatos do sexo masculino, mas, a partir de 28 de outubro de 1921, tornou-se mista quando da criação da Secção de Prendas e Economia Doméstica, voltada ao público feminino. De acordo com dados levantados por Fonseca (1961), a presença feminina nos quadros da escola era de grande destaque. Havia o predomínio da formação de professoras para lecionar em escolas primárias e em cursos de Datilografia, Estenografia, Moda e Economia Doméstica. A este respeito, Fonseca (1961, p. 599, grifo nosso) assim observa:

\footnotetext{
A Venceslau Brás teve sempre preponderância do elemento feminino entre os alunos matriculados, o que, de certa forma, prejudicou o principal fim colimado, que era a formação de mestres para o ensino profissional. Realmente, era muito mais necessário às várias escolas onde se aprendiam ofícios o preparo de pessoal capaz de ensinar trabalhos em madeira, em metal, ou eletricidade, do que a formação de professores de Datilografia, Estenografia, Modas ou Economia Doméstica.
}

O comentário de Fonseca (1961) denota a preocupação desse autor em apresentar a Escola Venceslau Brás como um apêndice das indústrias que nasciam e se ampliavam na época. Fica muito claro que, para o autor, essa escola deveria ter como finalidade a formação de professores que iriam preparar mão-de-obra especializada para suprir as exigências do mercado. 
A Escola Venceslau Brás, quando mista, funcionava em regime de externato e ofertava os seguintes cursos: Mecânica e Eletricidade, Trabalho em metal, Trabalho em madeira, Economia doméstica, Costura, Chapéus, Artes decorativas e Atividades comerciais. Como requisito para ingressar nela, era obrigatório comprovar a idade mínima de 12 anos e a inexistência de doenças infectocontagiosas e defeitos físicos (fato de denota a preocupação higienista dessa época), além de se submeter a um exame de proficiência composto de provas escritas e orais.

Os cursos tinham a duração de seis anos e possibilitavam aos seus egressos uma entrada bastante precoce nas atividades de ensino. A escola conferia os diplomas aos seus formandos de duas maneiras: considerando a idade mínima de 12 anos para o ingresso na instituição, aquele (a) aluno (a) que concluísse o quinto ano (de acordo com a especialização escolhida), receberia o diploma de mestre aos 17 anos; aquele (a) aluno (a) que, diplomado (a) mestre, concluísse o sexto ano, receberia o diploma de professor (a) aos 18 anos. Para ambos os casos havia ainda a exigência de uma prova didática.

Tal organização representava, portanto, um desafio pedagógico para os jovens mestres ou professores, como destaca Cunha (2005b, p. 85): "Não é difícil imaginar a dificuldade que teriam esses jovens mestre e professores no ensino de ofícios aos alunos das escolas de aprendizes artífices, não poucos dessa mesma idade”.

Durante seus vinte anos de funcionamento, a Escola Normal de Artes o Ofícios Venceslau Brás foi bastante questionada em razão de sua real finalidade, haja vista ter sido concebida como um espaço para a formação de mestres para as oficinas escolares, o que não veio a se concretizar devido a preponderância da presença feminina nessa escola e consequente consolidação dos cursos voltados para esse público específico.

Conforme salienta Fonseca (1961, p. 597), a realidade que se impôs deturpou aquela que tinha sido a função precípua dessa escola:

Fôra fundada principalmente para formar mestres para as oficinas escolares e tinha uma maioria de moças, estudando Datilografia e Estenografia, com o objetivo de obter diplomas de contador, ou se preparando para lecionar Costura e Bordados. Não era pròpriamente isto que o país esperava, mas sim a formação de homens que estivessem à altura de ensinar Mecânica, Eletricidade, Serralheria, Fundição, Marcenaria, Carpintaria, etc., enfim, de homens que pudessem fazer de seus alunos verdadeiros artífices para a indústria nacional.

O comentário tecido por Fonseca (1961) vai ao encontro do que se entendia como objetivo de uma escola de formação de trabalhadores: especializar mão de obra para atender às demandas do capital. Essa instituição de ensino deveria servir aos interesses da política econômica do governo Vargas (1930-1945) cuja meta era a nacionalização da economia brasileira por meio do modelo de substituição das importações. Daí o incentivo à criação de indústrias de base, necessárias para o impulso de outros ramos industriais. É nesse contexto que nascem, em princípios da década de 1940, a Companhia Siderúrgica Nacional, importante centro de produção de aço, e a Companhia Vale do Rio Doce. É válido também ressaltar a sistematização da Consolidação das Leis Trabalhistas (CLT), 
necessária para a organização das relações de trabalho que se estabeleciam no país. Era preciso disciplinar as relações entre capital e trabalho.

Dessa maneira, a Escola Normal de Artes e Ofícios Venceslau Brás, nos moldes que funcionava, não atendia às exigências do setor industrial e, por isso, o governo federal decidiu fecha-la em 1937. O prédio onde funcionava a escola foi demolido, dando lugar à Escola Técnica Nacional, instituída pelo Decreto Lei $\mathrm{n}^{\circ}$ 4.127, de 25 de fevereiro de 1942, e tinha como finalidades a formação de artífices, mestres e técnicos para a indústria nacional em crescimento, além da preparação de pessoal docente e administrativo para o Ensino Industrial. Esse ramo de ensino teve as bases de funcionamento e regime estabelecidos pela Lei Orgânica do Ensino Industrial, Decreto-Lei $n^{\circ} 4.073$, de 30 de janeiro de 1942.

Em se tratando da formação de professores, a Lei Orgânica do Ensino Industrial instituiu também o Ensino Pedagógico, abrangendo os cursos de Didática e o de Administração do Ensino Industrial. No primeiro, eram estudadas as disciplinas de Psicologia Educacional, Seleção Profissional, Metodologia e História da Indústria e do Ensino Industrial. No segundo, as disciplinas de Administração Educacional, Administração Escolar, Orientação e Seleção Profissional, Orientação Educacional e História da Indústria e do Ensino Industrial.

Embora tenha sido criado em 1942, o curso de Didática só começou a funcionar dez anos mais tarde. Assim, conforme Fonseca (1961, p. 602):

[...] ficou o país, durante aquêle lapso de tempo, sem nem uma só escola para formar o pessoal docente de que necessitava aquêle tipo de ensino. Se a situação, antes de 1937, já não era boa, pois existia um único estabelecimento para aquêle fim, depois dessa data a situação piorou, pois que nada veio em substituição ao que foi suprimido.

Em 13 de fevereiro de 1946, o Ministério da Educação e Saúde Pública, representado pelo ministro Raul Leitão da Cunha, firmou, com os Estados Unidos, um acordo de cooperação educacional que possibilitava a aproximação entre o Brasil e aquele país por meio do intercâmbio de educadores, ideias, experiências, estratégias e métodos pedagógicos. Sobre este acordo, Fonseca (1961, p. 564) esclarece:

[...] a iniciativa se propunha a desenvolver relações mais íntimas entre professôres do ensino industrial dos dois países, facilitar o intercâmbio e treinamento de brasileiros e americanos especializados em ensino industrial e a possibilitar outras atividades, no setor da educação industrial, e que pudessem interessar a ambas as partes.

Foi a partir desse acordo que nasceu a Comissão Brasileiro-Americana de Educação Industrial (CBAI), a qual formulou um programa de ação composto por doze pontos, que, de acordo com Fonseca (1961, p. 565) eram:

1. Desenvolvimento de um programa de treinamento e aperfeiçoamento de professores, instrutores e administradores;

2. Estudo e revisão do programa de ensino industrial; 


\section{Revista HIISTHADIBIR On-lime}

ISSN: 1676-2584

Artigo

doi: $10.20396 /$ rho.v17i2.8644682

3. Preparo e aquisição de material pedagógico;

4. Ampliação dos serviços de biblioteca, verificar a literatura técnica existente em espanhol e português, examinar a literatura técnica existente em inglês e providencia sobre a aquisição e tradução das obras que interessam ao nosso ensino industrial;

5. Determinar as necessidades do ensino industrial;

6. Aperfeiçoamento dos processos de organização e direção das oficinas;

7. Desenvolvimento de um programa de educação para prevenção de acidentes;

8. Aperfeiçoamento dos processos de administração e supervisão dos serviços centrais de administração escolar;

9. Aperfeiçoamento dos métodos de administração e supervisão das escolas;

10. Estudo dos critérios de registro de administradores e professores;

11. Seleção e orientação profissional e educacional dos alunos do ensino industrial;

12. Estudo das possibilidades do entrosamento das atividades de outros órgãos de educação industrial que não sejam administradas pelo Ministério da Educação, bem como a possibilidade de estabelecer outros programas de treinamento, tais como ensino para adultos, etc.

Amorin (2007) analisa essa aproximação entre o Brasil e os Estados Unidos. Para ele, a CBAI deve ser vista como um exemplo concreto da influência exercida por concepções educacionais elaboradas nos Estados Unidos sobre a educação brasileira no pós-guerra. Assim, a criação dessa Comissão tem relação direta com a chamada "Política da Boa Vizinhança", empreendida pelo governo estadunidense com seus vizinhos latinoamericanos durante a Segunda Guerra Mundial. Para esse autor, "[...] tal política seria o instrumento para o projeto de 'americanização' para o continente, cujo objetivo seria a adoção do chamado american way of life, tanto na América Latina, como posteriormente por todo o planeta". Logo, "[...] era extremamente importante a divulgação das vantagens da ideologia do americanismo para o subcontinente". (2007, p. 151).

Para o cumprimento de suas metas, o CBAI, entre janeiro e fevereiro de 1947, reuniu, no Rio de Janeiro, os diretores de estabelecimentos de ensino industrial. Dez desses diretores foram, em setembro do mesmo ano, para os Estados Unidos, com o objetivo de realizar um curso de especialização no Statte College, na Pensilvânia. Em fevereiro de 1948, um segundo grupo de diretores partiu para aquele país com esse mesmo fim. (FONSECA, 1961).

Também em 1947, o CBAI promoveu o primeiro curso de aperfeiçoamento destinado ao corpo docente do ensino industrial das escolas federais. $\mathrm{O}$ curso foi executado em dois momentos: no primeiro, os professores, concentrados na Escola Técnica Nacional, no Rio de Janeiro, realizaram estudos da língua inglesa, de conhecimentos gerais e técnicos e atualizaram e ampliaram seus conhecimentos a respeito do contexto socioeconômico brasileiro. No segundo, os professores selecionados na primeira fase, seguiram para os Estados Unidos onde receberam treinamento para o ensino industrial. Mesmo reconhecendo que houve falhas nessa segunda fase, Fonseca $(1961$, p. 567) destaca que o curso "[...] foi bastante vantajoso para o ensino industrial brasileiro, pelo maior descortino com que voltaram os professores e os seis técnicos". Em 1950, mais dois grupos de professores se dirigiram aos Estados Unidos para treinamentos. 
Paralelamente à ida dos professores e técnicos ao exterior, a CBAI empreendeu também cursos de aperfeiçoamento para professores em São Paulo, no Rio de Janeiro e em Recife. Em junho de 1948, o acordo de cooperação educacional chega ao fim, porém, foi prorrogado em 1948, 1951 e 1955. (FONSECA, 1961).

Após onze anos de trabalhos, a CBAI reavaliou os rumos de sua atuação e percebeu a necessidade de se estabelecer uma relação mais próxima com as escolas da rede. Dessa forma, em 1957, para promover uma intervenção de caráter mais técnico-pedagógica, foi instalado, em Curitiba-PR, o Centro de Pesquisas e Treinamento de Professores, oferecendo cursos de aperfeiçoamento para docentes de diferentes especialidades e oriundos de diversas localidades do país.

Todavia, convém ressaltar que, mesmo antes do funcionamento dos Cursos Pedagógicos da Escola Técnica Nacional e dos cursos de aperfeiçoamento promovidos pela CBAI, houve outras iniciativas importantes para formação de professores para a Educação Profissional, dentre as quais destacamos: as criações da Escola Normal de Artes e Ofícios, em Araraquara, da Escola Profissional Feminina Carlos Campos e do Instituto Pedagógico do Ensino Industrial, ambos na Capital Paulista, e ainda do Curso NormalProfissional das Escolas Femininas Fluminenses, no Rio de Janeiro.

A partir da década de 1960, o MEC passou a regular o exercício do magistério na Educação Profissional, emitindo, por meio de portarias, as normas e exigências para o registro de professores para lecionar nessa modalidade. No ano seguinte, a LDB, Lei $\mathrm{n}^{\circ}$ 4.024/61, estabeleceu, em seu artigo 59, a separação entre os locais de formação dos professores do Ensino Médio (Faculdades de Filosofia, Ciências e Letras) daqueles destinados aos professores do Ensino Técnico (cursos especiais de educação técnica).

Dois aspectos são merecedores de destaque com relação a esse artigo da LDB de 1961. O primeiro, diz respeito à dualidade na formação de professores, haja vista que esta estabelece locais de formação diferentes para professores de um mesmo nível de ensino. Dessa forma, pela via legal, separavam-se os espaços destinados à formação de professores. Na forma da Lei, o Ensino Médio propedêutico e o Ensino Técnico são tratados de forma distinta e independentes, como se não fossem ambos pertencentes ao mesmo nível.

O segundo destaque que damos àquele artigo diz respeito à adjetivação dada a esses cursos: eram qualificados como "especiais". O adjetivo "especial", empregado pela LDB, denuncia a condição de transitoriedade das propostas de formação de professores para a Educação Profissional. Tal situação vai se repetir e, até mesmo, perpetuar-se na historicidade dessa modalidade, como destaca Machado (2013, p. 350): "[...] até hoje a referência mais forte que se tem é a de que a formação docente para a educação profissional deve se dar em cursos especiais".

Sobre os cursos "especiais", previstos no artigo 59 da LDB de 1961, o Parecer CFE $n^{\circ} 12 / 1967$, este criado no contexto da ditadura civil-militar (1964-1985), veio explicar que tinham como objetivo formar professores de disciplinas específicas. Isso significa que, 
para cada disciplina dos cursos técnicos, haveria também um curso especial de formação de professores.

É importante destacar que os governos da ditadura civil-militar optaram por uma estratégia de desenvolvimento voltada para grandes projetos nacionais, emergindo a necessidade de executar programas que requeriam mão de obra em massa e qualificada. Daí a revitalização do Programa Intensivo de Mão de obra - PIPMO (concebido pelo governo de João Goulart em 1963 e executado durante a ditadura militar até 1982), cujo treinamento era dado pelas instituições voltadas para a formação profissional, como o Sistema S e as Escolas Técnicas Federais. Conforme Manfredi (2002, p. 104) "[...] os cursos tinham duração breve e abarcavam um conteúdo reduzido, prático e operacional". Para essa autora, o caráter tecnicista dos projetos de desenvolvimento praticados nesse período "[...] fortaleceu o Sistema $\mathrm{S}$ e as iniciativas das empresas privadas e estatais, por intermédio do PIPMO e da Lei 6.297/57, que concedeu incentivos fiscais para que as próprias empresas desenvolvessem seus projetos de formação profissional”. (2002, p. 104).

Evidentemente, essa política econômica do governo militar não deixou de exercer influências sobre a formação de docentes que lecionariam nesses cursos. Era preciso criar ou ajustar a legislação educacional para que esta atendesse a esse projeto político. Logo, a formação de professores deveria ser era tão urgente e rápida quanto os cursos em que eles atuariam.

Em 1968, a Portaria no 111/68 definiu que os cursos "especiais" destinavam-se à formação de professores para as disciplinas específicas e que poderiam cursá-los tanto aqueles que possuíam diploma de nível superior, quanto aqueles que possuíam diploma de nível técnico, mas, para estes últimos, havia a exigência de possuir, em seu currículo, a formação na disciplina a qual se candidatavam a lecionar. Além disso, a Portaria determinava a duração mínima dos cursos especiais em 700 horas.

Também em 1968, o Conselho Federal de Educação (CFE) aprovou o Parecer $n^{\circ}$ 479, o qual estabelecia que, a partir de então, na formação de professores para as disciplinas específicas dos cursos técnicos, era necessário cumprir um currículo mínimo e obedecer à duração prevista para os cursos do Ensino Médio fixada pelo Parecer no 262/62. Significava, portanto, a adoção do esquema " $3+1$ ": três anos para o núcleo comum e um para a parte profissional. Para Machado (2008a, p. 72), “[...] esse parecer tinha a intenção de fazer diminuir a separação que se estabeleceu entre formação docente para o ensino técnico e formação docente para o ensino médio".

A Lei da Reforma Universitária, Lei $\mathrm{n}^{\circ}$ 5.540/68, imprimiu maiores exigências para o magistério de $2^{\circ}$ grau, estabelecendo, em seu artigo 30, que a formação de professores para esse grau deveria se dar em cursos de nível superior para disciplinas gerais ou técnicas. Vejamos, pois, o texto do dispositivo legal:

Art. 30: A formação de professores para o ensino de segundo grau, de disciplinas gerais ou técnicas, bem como o preparo de especialistas destinados ao trabalho de planejamento, supervisão, administração inspeção e orientação no âmbito de escolas e sistemas escolares, far-se-á em nível superior. (BRASIL, 1968). 
Porém, por falta de condições objetivas para o cumprimento desse dispositivo e ainda em função do interesse dos governos militares em ampliar a industrialização brasileira e atrair empresas multinacionais, em 1969, o Decreto Lei ${ }^{\circ}$ 464/69flexibilizou a determinação da Lei n ${ }^{\circ} 5.540 / 68$ nos seguintes termos:

\begin{abstract}
Enquanto não houver em número bastante, os professores e especialistas a que se refere o artigo 30 da Lei $n^{\circ} 5.540$ de 28 de novembro de 1968, a habilitação para as respectivas funções será feita mediante exame de suficiência realizado em instituições oficiais de ensino superior indicadas pelo Conselho Federal de Educação.

Parágrafo Único: Nos cursos destinados à formação de professores de disciplinas especiais no ensino técnico, bem como de administradores e demais especialistas para o ensino primário, os docentes que se encontravam em exercício na data da publicação da Lei 5.540, de 28 de novembro de 1968, sem preencher os requisitos mínimos para o exercício do magistério em nível superior, deverão regularizar a sua situação no prazo de cinco anos. (BRASIL, 1969).
\end{abstract}

A adoção dessa estratégia serviu, portanto, para regularizar a situação de um grande contingente de professores, administradores e especialistas que, à época da promulgação da Lei 5.540/68, estavam em exercício, mas não tinham o requisito exigido pela legislação. Em se tratando da questão da formação de professores para o Ensino Técnico, era grande o contingente de professores em situação irregular perante as exigências da lei para o exercício do magistério nessa modalidade. Para suprir essa defasagem, foi instituída, por meio do Decreto Lei $n^{\circ}$ 616/69, a Fundação Centro Nacional de Aperfeiçoamento de Pessoal para Formação Profissional (CENAFOR), diretamente ligado ao MEC, tendo como objetivos, de acordo com o artigo $3^{\circ}$ :

I. Preparar, aperfeiçoar, especializar e qualificar:

(a) Professores de disciplinas específicas de cursos profissionalizantes e de educação para o trabalho, de $2^{\circ}$ grau. [...]

(c) Pessoal de supervisão e direção de programas do ensino profissional em escolas, centros de treinamento e empresas [...]. (BRASIL, 1969).

Outra proposição importante do MEC foi a criação, por meio da Portaria Ministerial n $\mathrm{n}^{\mathbf{0}}$ 339/70, dos cursos emergenciais conhecidos como "Esquemas I e II". O Esquema I era destinado à complementação pedagógica de portadores de diplomas de nível superior, enquanto que o Esquema II era destinado aos portadores de diploma técnico industrial de nível médio. Para estes últimos, além das disciplinas do Esquema I eram necessárias também disciplinas de conteúdos correlativas. (MACHADO, 2008a, p. 73).

Em 1970, o Parecer CFE $n^{\circ}$ 74/70 estabeleceu que os cursos de formação para o ensino técnico deveriam ter 1600 horas/aula a serem integralizadas em nove meses. Para os candidatos que tivessem diploma de formação técnica, o curso poderia ser reduzido para 800 horas/aula a ser integralizado em cinco meses. (MACHADO, 2013). Percebe-se aí a urgência que o governo militar tinha em formar esses professores, uma necessidade imposta carência de mão-de-obra qualificada para atender a um parque industrial que crescia principalmente em função do incentivo dado pelo governo à vinda de empresas multinacionais. Esse fato também explica a criação da Lei 5.592/71 que estabeleceu, dentre outras coisas, a profissionalização obrigatória no ensino de segundo grau. Ou seja, no 
contexto do "milagre econômico brasileiro"3 era necessário formar, o mais rápido possível, trabalhadores para atender às demandas do mercado em expansão.

Ao longo da década de 1970 outras medidas foram tomadas pelo MEC para a formação de professores para a Educação Profissional. Porém, os Esquemas I e II vigoraram até que a Portaria $n^{\circ} 396 / 77$ criou a licenciatura plena para a formação especial de $2^{\circ}$ grau, paralelamente com a Resolução $n^{\circ} 3 / 77$, que fixou o currículo mínimo para essa graduação e determinou que as instituições de ensino ofertantes dos referidos esquemas, fizessem, no prazo máximo de três anos, as adaptações necessárias para a transformação destes em licenciaturas. Diante das dificuldades enfrentadas para a implantação dessas licenciaturas e, considerando o prazo dado pela Resolução, foi instituído, pelo Parecer $n^{\circ}$ 47/79, o Plano de Curso Emergencial para a Formação de Professores para as Disciplinas Especiais nos termos da Portaria no 396/77.

Com a estabilidade da economia, gerada pelo chamado "milagre econômico brasileiro", reforçaram-se os esforços para a expansão da indústria de bens de consumo duráveis, dirigido ao consumo das classes média e alta da sociedade e viabilizada pelos grandes investimentos estrangeiros e do Estado. Era imperioso formar mão de obra de modo intenso e rápido. Coadunando com esse viés tecnicista, foi criada, no governo do presidente Garrastazu Médici, a Lei № 5.692, de 11 de agosto de 1971, para reformar o Ensino $1^{\circ}$ e $2^{\circ}$ graus. Esta lei promoveu, dentre outras inovações, a profissionalização universal e compulsória ${ }^{4}$ para todo o ensino médio, delegando à educação a função de qualificar os recursos humanos para atender às necessidades do mercado de trabalho em plena expansão. A lei também gerou uma demanda por formação de professores para as disciplinas especializadas e muitas instituições de ensino superior demonstraram interesse nessas ofertas emergenciais. Por isso, mais tarde, o CFE foi obrigado a fazer algumas alterações e adaptações nos termos da Resolução n ${ }^{\circ}$ 3/77 que foram estabelecidas pelo CFE no Parecer no 1.092/80 e na Resolução nº 1/81.

Na década de 1990, o governo de Fernando Henrique Cardoso, em nome de um suposto desenvolvimento econômico, adotou os ideais neoliberais reservando ao Estado um papel de coadjuvante na garantia dos direitos sociais, sobrepondo, assim, os interesses do capital aos interesses ou prioridades sociais. Nesse contexto, o trabalhador é visto como um instrumento do sistema produtivo e, dele, exige-se cada vez mais desempenho, produtividade e competência. Para isso, precisa apenas ser treinado e instrumentalizado sem conhecer, no entanto, os fundamentos científicos e tecnológicos envolvidos nos processos produtivos.

Para tal intento, em 18 de abril de 1997, foi publicado o Decreto $\mathrm{n}^{\mathbf{0}} 2.208$, cuja característica principal era a oficialização do divórcio entre a formação geral e a profissional. O referido decreto suscitou muitas críticas pela maneira como tratou a formação de professores para as disciplinas técnicas, pois nele fica claro que, na seleção dos professores, a formação advinda da experiência prática tem mais valor que aquela construída em bases teórico-pedagógicas. (MACHADO, 2013). O artigo no 9 desse decreto expressa que: 


\section{Revista IIISTFIDIBR On-lime}

As disciplinas do currículo do ensino técnico serão ministradas por professores, instrutores e monitores selecionados, principalmente, em função de sua experiência profissional, que deverão ser preparados para o magistério, previamente ou em serviço, através de cursos regulares de licenciatura ou de programas especiais de formação pedagógica. (BRASIL, 1997, grifo nosso).

Também em 1997, o Conselho Nacional de Educação regulamentou, por meio da Resolução no 2/97, os Programas Especiais de Formação Pedagógica de docentes para as disciplinas do currículo do Ensino Fundamental, do Ensino Médio e da Educação Profissional em nível médio, objetivando formar aqueles que possuíssem diploma de curso superior para o exercício da docência. A Resolução também definiu que a carga horária mínima admitida seria de 540 horas, incluídas nestas a parte teórica, que poderia ser oferecida à distância, e prática, que, nos termos desse documento, passou a ter duração de 300 horas. Como podemos ver, essa determinação representou um decréscimo na carga horária para os cursos especiais de formação de professores para a Educação Profissional.

Sob essa ótica, o papel do professor seria o de instrumentalizar os alunos com técnicas laborais acríticas, contribuindo fortemente para manutenção do status quo vigente. Daí se justifica que, também nesse período, as políticas de formação de professores não tenham sido colocadas como prioridade. As poucas iniciativas nesse campo foram regulamentadas e/ou normatizadas por meio de programas de caráter emergenciais e, por isso, não avançaram.

O século XXI inicia com novos debates e perspectivas. A eleição do presidente Luiz Inácio Lula da Silva inaugura um novo momento para a Educação Profissional no Brasil. Com a retomada dos investimentos e iniciativas em prol das instituições federais de ensino, em 2004, foi posto fim no Decreto 2.208/97, e, no ano seguinte, promulgada a Lei $\mathrm{n}^{\mathrm{o}}$. 11.195/05, dando início à expansão da Rede Federal de Educação Profissional e Tecnológica no país, depois de ter passado, no governo anterior, por um momento de estagnação em função de uma concepção privatista do ensino. Com essa Lei, lança-se, em nível nacional, um plano para expandir e interiorizar a Educação Profissional em todo o país.

Com essa expansão, a maior já vista na história da Educação Profissional no Brasil, eleva-se a oferta de vagas para o ingresso nos cursos técnicos, tecnológicos, de graduação e de pós-graduação, implicando a contratação de um elevado número de professores licenciados e bacharéis para atuar nos campi existentes e recém-criados. Entretanto, essa expansão ampliou ainda mais o desafio de formar professores para atuar na Educação Profissional. Como afirma Machado (2008b, p. 14): "A carência de pessoal docente qualificado tem se constituído num dos pontos nevrálgicos mais importantes que estrangulam a expansão da educação profissional no país".

Para termos uma ideia da dimensão desse desafio, devemos considerar que a forma pela qual se organiza a Educação Profissional no Brasil hoje é bastante singular. Essa modalidade de ensino e educação conta com uma grande diversidade de currículos, redes ofertantes, áreas profissionais ou eixos tecnológicos, além da relação que precisa estabelecer com outras modalidades, como, por exemplo, a Educação de Jovens e Adultos. 
Além disso, é sabido que geralmente os professores que ingressam na Rede Federal de Educação Profissional e Tecnológica não têm uma formação acadêmica para lecionar nos cursos técnicos e tecnológicos: os professores bacharéis chegam sem uma base pedagógica; já os licenciados raramente têm nos currículos da Educação Superior estudos referentes à temática trabalho e educação. Tudo isso traz implicações para o trabalho docente na Educação Profissional, haja vista ser o professor, o responsável pela condução do processo de ensino-aprendizagem necessitando, portanto, ser formado e/ou preparado para essa função. Dessa forma, "[...] dada esta diversidade de situações e dispersão das soluções que vêm sendo praticadas, os professores da educação profissional são levados a atuar com um mínimo de orientações pedagógicas e técnicas”. (MACHADO, 2008a, p. $17)$.

A dificuldade na proposição e implementação de estratégias de formação para os professores que lecionam nessa modalidade acontece, principalmente, porque existem diferentes grupos para os quais se destina essa formação. Há grupo dos docentes não graduados que atuam na Educação Profissional e lecionam em escolas da rede privada ou em ONGs; os graduados que atuam na Educação Profissional, mas não têm formação específica nessa modalidade, como é o caso dos bacharéis; e o grupo dos licenciados para ensinar as disciplinas da educação básica, que, apesar de terem sido formados para o exercício da docência, não tiveram, em sua formação inicial, nenhuma aproximação com a Educação Profissional. Podemos ainda acrescentar os futuros profissionais que ainda começarão a formação inicial docente. (MOURA, 2008).

Em relação aos espaços onde pode ocorrer a formação para a docência na Educação Profissional, encontramos, hoje, algumas ofertas com número bastante reduzido em programas especiais, formação em serviço, à distância e um número menor ainda de licenciaturas. Nesse contexto, as licenciaturas vêm sendo defendidas como espaços privilegiados para a formação inicial dos docentes. Tal defesa considera suas prováveis contribuições para a profissionalização desses docentes, para o desenvolvimento de pedagogias apropriadas às especificidades da Educação Profissional, para o intercâmbio de experiências nesse campo, para o desenvolvimento da reflexão pedagógica sobre a prática nessa área e ainda como espaço profícuo para o fortalecimento entre ensino, pesquisa e extensão. (MACHADO, 2008b).

No tocante à essa formação, é importante discutir que eixos devem ser considerados, bem como o perfil docente a ser formado. Estes eixos devem contemplar uma a formação didático-político-pedagógica e a área de conhecimento específica, ambos em permanente diálogo com a sociedade em geral e o mundo do trabalho. (MOURA, 2008).

Ampliando esse debate, Santos (2008), afirma que a definição de tais eixos não deve implicar na segmentação de percursos formativos. A mesma autora, afirma ainda que a formação deve contemplar:

a) uma concepção de docência que se sustente numa base humanista; 


\section{Revista IIISTFEIDIBR Dndline}

b) uma concepção de docência que impregne a prática desse profissional quando sua atuação se dá no mundo do trabalho;

c) políticas públicas, e, sobretudo de Educação Profissional e Tecnológica;

d) o papel dos profissionais da educação, em geral, e EPT, em particular;

e) a profissionalização do docente da EPT: formação inicial e continuada, carreira, remuneração e condições de trabalho;

f) uma formação com ênfase na concepção de unidade de ensino e pesquisa;

g) ênfase, também, em desenvolvimento e inovação. (2008, p. 134).

Atualmente, as exigências relativas ao perfil para a docência na Educação Profissional estão mais elevadas, considerando-se que o professor dessa modalidade:

[...] não pode moldar-se à feição de transmissor de conteúdos definidos por especialistas externos, mas compor-se por características em que seu papel de professor se combine com as posturas de: a) Intelectual; b) Problematizador; c) Mediador do processo ensino-aprendizagem; d) Promotor do exercício de liderança intelectual; e) Orientador sobre o compromisso social que a ideia de cidadania plena contém; f) Orientador sobre o comportamento técnico dentro de sua área de conhecimento. (ARAÚJO, 2008, p. 59).

Portanto, não há espaço para o modelo artesanal do mestre da oficina-escola, o das séries metódicas, a ideia de que para ensinar é necessário apenas o domínio da prática, ou seja, saber fazer. Por isso, o trabalho desse professor deve ser forjado a partir de uma formação que possibilite aos alunos o desenvolvimento da criatividade, do pensamento crítico, do trabalho intelectual. Sua formação deve ser crítica, reflexiva e dotada de responsabilidade social. (MOURA, 2008).

Nesse sentido, ao discutir o perfil do docente a ser formado para a Educação Profissional, Machado (2008b, p. 17) destaca que este:

[...] seja, essencialmente, um sujeito da reflexão e da pesquisa, aberto ao trabalho coletivo e à ação crítica e cooperativa, comprometido com sua atualização permanente na área de formação específica e pedagógica, que tem plena compreensão do mundo do trabalho e das redes de relações que envolvem as modalidades, níveis e instâncias educacionais, conhecimento da sua profissão, de suas técnicas, bases tecnológicas e valores do trabalho, bem como dos limites e possibilidades do trabalho docente que realiza e precisa realizar.

Além desse pressuposto básico, a mesma autora aponta outros aspectos que podem ser entendidos como constitutivos de um perfil para a docência na Educação Profissional. Trata-se, portanto, de um profissional que:

[...] sabe o que, como e por que fazer e que aprendeu a ensinar, para desenvolver idônea e adequadamente outros profissionais;

[...] deve ter a capacidade de elaborar estratégias e estabelecer formas criativas de ensino aprendizagem; prever condições necessárias ao desenvolvimento da educação profissional, considerando suas peculiaridades [...];

[...] realizar um trabalho mais integrado e interdisciplinar; promover transposições didáticas contextualizadas e vinculadas às atividades práticas e de pesquisa; 


\title{
Revista HIISTIEIDIBIR On-lime
}

[...] deve ser capaz de permitir que seus alunos compreendam de forma reflexiva e crítica, os mundos do trabalho, dos objetos e dos sistemas tecnológicos dentro dos quais estes evoluem [...];

[...] deve ser capaz de descrever práticas profissionais (como, porque e dentro de que condições uma atividade é realizada), de levar em conta o uso que quer fazer desta descrição no processo de ensino-aprendizagem e de estabelecer a diferença entre ensinar práticas e ensinar os saberes sobres estas práticas. (MACHADO, 2008b, p. 17-18).

Importa ressaltar que a formação de professores para a Educação Profissional deve considerar as especificidades e complexidades do trabalho docente nessa área e romper com a fragmentação e a improvisação que marcaram historicamente essa modalidade de ensino e educação no Brasil. Entendemos que as ações para a formação de professores devem se constituir em políticas públicas, não podendo ter caráter pontual e assistemático. Assim, é premente a concepção e implementação de uma política nacional, ampla e contínua de formação docente para a Educação Profissional, considerando as especificidades e a complexidade da área. A ausência dessa política confere a essa modalidade uma condição de "invisibilidade", conforme nos aponta Costa (2016, p. 126):

\begin{abstract}
A formação de professores vem constituindo a sua identidade num processo de (re)construção de normativas oficiais que ora se fazem em nível médio, ora se fazem pela exigência do nível superior. Nesse ir e vir das regulamentações para a docência, a profissão professor para EPT se torna invisível, porque não se evidência construção identitária para esta modalidade de ensino, porém, se manifesta os paradoxos e os desencontros no devir dessa modalidade de ensino, que são na realidade migrados da educação superior em geral e também da formação de professores para a educação básica.
\end{abstract}

Superar a "invisibilidade" no âmbito das políticas educacionais e construir uma identidade para essa modalidade tão singular, remete-nos a inúmeros desafios, dentre os quais: redefinir o modelo de formação de professores em curso no interior das nossas universidades, que vinculadas fortemente a interesses mercadológicos, transformam esses futuros profissionais em operários da produtividade e competitividade acadêmica.

Esse viés que subordina a educação aos interesses do mercado, atinge, numa espécie de efeito cascata: a educação básica como um todo, e principalmente a Educação Profissional, onde grande parte dos professores, a reboque de uma frágil formação, feita na maioria das vezes, por meio de programas e projetos de caráter emergencial, compensatório e produtivista, reproduzem a lógica de subordinação do ensino técnico ou profissional às demandas do mercado.

$\mathrm{Na}$ contramão dessa condição de subordinação e acomodação ao mercado de trabalho, outro desafio é criar políticas de formação de professores para a Educação Profissional nas quais a tônica seja a reflexão crítica sobre dimensões como capital/trabalho, educação/trabalho, homem/sociedade, dentre outras. Assim formados, esses docentes desempenharão a árdua tarefa de inverter a lógica: aprender e ensinar a enfrentar as contradições do mercado de trabalho. Por fim, façamos coro às palavras de Ramos (2008, p. 23), para quem a escola e os sistemas de ensino necessitam de "uma visão crítica do mercado de trabalho e construir o processo formativo no qual, ao tempo em que 
proporcionam acesso aos conhecimentos, contribuam para que o sujeito se insira no mundo do trabalho e também questione a lógica desse mesmo mercado".

\section{CONSIDERAÇÕES FINAIS}

Ao compreendermos a formação de docentes para a Educação Profissional, no Brasil, em uma perspectiva histórica, vemos que as propostas ou ações para essa formação não foram pensadas e organizadas de maneira sistemática. Pelo contrário, invariavelmente, surgiram em atendimento às demandas legais em contextos bem específicos. O que percebemos, na verdade, é a prática de ações pontuais, emergenciais, "especiais", geralmente em função da rapidez com que se quer ter um profissional moldado às exigências do mercado. Podem ser consideradas, segundo Oliveira (2011, p. 329), como políticas de governo e não de Estado, haja vista que as primeiras são aquelas em que o “ Executivo decide num processo elementar de formulação e implementação de determinadas medidas e programas, visando responder às demandas da agenda política interna, ainda que envolvam escolhas complexas".

Ao contrário disso, a Educação Profissional exige uma formação docente consistente, sistemática e capaz de permitir a articulação e o desenvolvimento equilibrado de saberes gerais e técnicos, estes específicos de um campo da ciência. Ou seja, necessita de uma formação que se construa e se fundamente na contribuição das diversas áreas do conhecimento, que devem se articular formando um construto teórico que possibilite um movimento dialético entre teoria e prática. Logo, esse professor deve estar consciente do papel que desempenha na formação de técnicos que se insiram no mundo do trabalho como um profissional cidadão e não como um mero executor de tarefas exigidas pelo mercado.

Diante disso, enfatizamos que a natureza peculiar do trabalho docente na Educação Profissional (em cursos de Ensino Médio, seja integrado, subsequente ou concomitante; no Proeja, no Pronatec, dentre tantos outros espaços de ensino-aprendizagem nessa modalidade) torna-se um desafio quando são criadas propostas de formação e qualificação para esses professores. Que tipo de professor se deseja formar? Para que projeto de sociedade? Esses questionamentos nos conduzem às preocupações expressas nas produções acadêmicas de grande parte dos estudiosos da Educação Profissional e que podem ser sintetizadas nas palavras de Costa (2016, p. 21) ao defender um tipo de formação balizada "[...] por princípios de uma Educação Profissional e Tecnológica que supere os limites da aquisição de uma técnica para suprir a demanda dos postos de trabalho que, cada dia mais, vem incorporando novas tecnologias".

\section{REFERÊNCIAS}


AMORIM, M. L. O surgimento da comissão brasileiro-americana de educação industrial (CBAI). Revista História da Educação, Porto Alegre, v. 11, n. 23, p. 149-171, set./dez. 2007.

ARAÚJO, R. M. L. Formação de docentes para a educação profissional e tecnológica: por uma pedagogia integradora da educação profissional. Trabalho e Educação, Campinas, v. 17, n. 2, p. 53-63, maio/ago. 2008.

BRASIL. Decreto Lei n ${ }^{\circ} 464$, de 11 de fevereiro de 1969. Estabelece normas complementares à Lei ${ }^{\circ} 5.540$, de 28 de novembro de 1968, e dá outras providências. Disponível em: <http://www.planalto.gov.br/ccivil_03/decreto-lei/1965-1988/ Del0464 .htm>. Acesso em: 27 abr. 2017.

BRASIL. Decreto Lei no 616, de 09 de junho de 1969. Institui o Centro nacional de Aperfeiçoamento de Pessoal para a Formação Profissional. - CENAFOR e dá outras providências. Disponível em: <http://www.planalto.gov.br/ccivil_03/Decreto-lei/19651988/Del0616.htm>. Acesso em: 27 abr. 2017.

BRASIL. Decreto Lei no 2.208, de 17 de abril de 1997. Regulamenta o $\S 2^{\circ}$ do Art. 36 e os Arts. 39 a 42 da Lei ${ }^{\circ} 9.394$ de, 20 de dezembro de 1997, que estabelece as diretrizes e bases da educação nacional. Disponível em: <http://www.planalto.gov.br/ccivil_03/ decreto/d2208.htm>. Acesso em: 27 abr. 2017.

BRASIL. Lei ${ }^{\circ} 5.540$, de 28 de novembro de 1968. Fixa normas de organização e funcionamento do ensino superior e sua articulação com a escola média, e dá outras providências. Disponível em: <http://www.planalto.gov.br/ccivil_03/leis/15540.htm>. Acesso em: 29 mar. 2016.

BRASIL. Lei ${ }^{\circ} 5.692$, de 11 de agosto de 1971. Fixa diretrizes e bases para o ensino de $1^{\circ}$ e $2^{\circ}$ graus, e dá outras providências. Disponível em: <http://www2.camara.leg.br/legin/fed /lei/1970-1979/lei-5692-11-agosto-1971-357752-publicacaooriginal-1-pl.html>. Acesso em: 20 jun. 2017.

COSTA, M. A. Políticas de formação docente para a educação profissional: realidade ou utopia? Curitiba: Appris Editora, 2016.

CUNHA, L. A. O ensino de ofícios artesanais e manufatureiros no Brasil escravocrata. 2. ed. São Paulo: Unesp; Brasília: Flacso, 2005a.

CUNHA, L. A. O ensino de ofícios nos primórdios da industrialização. São Paulo: Unesp; Brasília, 2005b.

FONSECA, C. S. História do ensino industrial no Brasil. Rio de Janeiro, 1961.

GIL, A. C. Métodos e técnicas de pesquisa social. 6. ed. São Paulo: Atlas, 2012. 
GONSALVES, E. P. Conversas sobre iniciação à pesquisa científica. 4. ed. Campinas: Alínea, 2007.

INSTITUTO NACIONAL DE ESTUDOS E PESQUISAS EDUCACIONAIS. Brasília, 1982. Disponível em: <http://www.dominiopublico.gov.br/download/texto/me002257 .pdf>. Acesso em: 20 jun. 2017.

KUENZER, A. Z. Formação de professores para educação profissional e tecnológica: perspectivas históricas e desafios contemporâneos. Educação Superior em Debate, Brasília: Instituto Nacional de Estudos e Pesquisas Educacionais Anísio Teixeira, v. 8, p. 19-40, 2008.

MACHADO, L. R. S. Formação de professores para a educação profissional e tecnológica: perspectivas históricas e desafios contemporâneos. Educação Superior em Debate, Brasília: Instituto Nacional de Estudos e Pesquisas Educacionais Anísio Teixeira, v. 8, p. 67-83, 2008a.

MACHADO, L. R. S. Formação de professores para a educação profissional e tecnológica: perspectivas históricas e desafios contemporâneos. In: MOURA, D. H. (Org.). Produção do conhecimento, políticas públicas e formação docente em educação profissional. Campinas: Mercado das Letras, 2013, p. 347-362.

MACHADO, L. R. S. Diferenciais inovadores na formação de professores para a educação profissional. Revista Brasileira da Educação Profissional e Tecnológica. Brasília, DF, MEC, SETEC. v. 1, n. 1, p. 8-22, jun. 2008b.

MANFREDI, S. M. Educação profissional no Brasil. São Paulo: Cortez, 2002.

MOURA, D. H. A formação de docentes para a educação profissional e tecnológica.

Revista Brasileira da Educação Profissional e Tecnológica, Brasília, DF, MEC, SETEC, v. 1, n. 1, p. 23-38, jun. 2008.

OLIVEIRA, A. S. A formação do professor para a educação profissional: mapeando a produção bibliográfica. 2016. 136 f. Dissertação (Mestrado em Educação) - Universidade Estadual do Sudoeste da Bahia, Programa de Pós-graduação em Educação, Vitória da Conquista, 2016.

OLIVEIRA, D. A. Das políticas de governo às políticas de estado: reflexões sobre a atual agenda educacional brasileira. Educação e sociedade, Campinas, v. 32, n. 115, p. 323337, abr./jun. 2011.

RAMOS, M. Concepção do ensino médio integrado. 2008. Disponível em: <http://www. iiep.org.br/curriculo_integrado.pdf>. Acesso em: 19 abr. 2017.

SANTOS, H. H. Formação de professores para a educação profissional e tecnológica no âmbito da legislação educacional brasileira e do ensino superior no Brasil. Educação Superior em Debate, v. 8, p. 125-139, 2008. 
URBANETZ, S. T. Uma ilustre desconhecida: a formação docente para a educação profissional. Revista Diálogo Educacional, Curitiba, v. 12, n. 37, p. 863-883, set./dez. 2012.

\section{Notas}

${ }^{1}$ Licenciado em História (UFPB), doutor em Educação (UFRN) e professor do Instituto Federal de Educação, Ciência e Tecnologia do Rio Grande do Norte, Campus Mossoró. Leciona no Programa de PósGraduação em Educação Profisssional e Tecnológica (ProfEPT - Mestrado Profissional em Rede Nacional) e Programa de Pós-Graduação em Ensino (IFRN/UERN/UFERSA).

${ }^{2}$ Licenciada em Pedagogia (UERN) e mestre em Educação (IFRN). Pedagoga do Instituto Federal de Educação, Ciência e Tecnologia do Rio Grande do Norte, Campus Parnamirim.

3 "Milagre econômico brasileiro" é um termo comumente usado para se referir ao rápido crescimento econômico verificado entre 1968 e 1973, período em que o Brasil alcançou taxas médias de crescimento muito elevadas, em torno de $11 \%$.

${ }^{4}$ A Lei $\mathrm{N}^{\circ} 5.692 / 71$ estabeleceu a obrigatoriedade do ensino profissionalizante. O parágrafo $5^{\circ}$ do artigo $2^{\circ}$ dessa lei explicita que: "A parte de formação especial [para o trabalho] de currículo: a) terá o objetivo de sondagem de aptidões e iniciação para o trabalho, no ensino de $1^{\circ}$ grau, e de habilitação profissional, no ensino de $2^{\circ}$ grau; b) será fixada, quando se destina a iniciação e habilitação profissional, em consonância com as necessidades do mercado de trabalho local ou regional, à vista de levantamentos periodicamente renovados" (BRASIL, 1971). Uma análise da profissionalização do ensino presente na Lei $\mathrm{N}^{\circ}$ 5.692/71 foi realizada pelo Instituto Nacional de Estudos e Pesquisas Educacionais (INEP), em 1982 (INSTITUTO NACIONAL..., 1982).

Submetido em: 31/03/2016

Aprovado em: 27/06/2017 